Note

\section{Changes in Rigor-mortis Progress of Carp Induced by Temperature Acclimation}

\author{
Shugo Watabe, Gyu-Chul Hwang, \\ Hideki Ushio and Kanehisa HaSHimoto* \\ Laboratory of Marine Biochemistry, Faculty of \\ Agriculture, The University of Tokyo, \\ Bunkyo-ku, Tokyo 113, Japan
}

Received June 22, 1989

Wide changes in body temperature are experienced seasonally by poikilotherms, especially eurythermal temperate zone fish such as carp and goldfish. In these fish species, acclimation leads to compensatory changes of myofibrillar ATPase activity, while no changes are recorded in others. ${ }^{11}$ Changes in myofibrillar ATPase by thermal acclimation would possibly influence postmortem changes, since rigor-mortis proceeds depending on the degradation rate of ATP in the muscle. ${ }^{2)}$ Recently we have found that rigor-mortis acceleration of fish stored at $0^{\circ} \mathrm{C}$ is at least partly related to a decrease in $\mathrm{Ca}^{2+}$ uptake ability of the sarcoplasmic reticulum (SR) ${ }^{3)} \mathrm{A}$ $\mathrm{Ca}^{2+}$ concentration increase inside myofibrils at this temperature would activate myofibrillar $\mathrm{Mg}^{2+}$-ATPase, ${ }^{4)}$ thus accelerating ATP degradation. The purpose of this study was to examine the effects of thermal acclimation on rigormortis progress of carp in association with changes in myofibrillar ATPase activity and SR $\mathrm{Ca}^{2+}$ uptake ability.

Groups of similar-sized carp, Cyprinus carpio (0.8$1.0 \mathrm{~kg}$ in body weight), maintained at $16-17^{\circ} \mathrm{C}$ for a few months were obtained from a local supplier and acclimated to either 10 or $30^{\circ} \mathrm{C}$ for a minimum of 5 weeks in tanks of circulating aerated tap water. All fish were fed ad libitum daily with a commercial pellet feed. After being killed by decapitation, fish were bled, packed into plastic bags and stored in ice-cold water. The rigor index of fish, used as a parameter of rigor tension, was measured by the sag of the tail when the fish were placed on a horizontal table with half the body spread out. ${ }^{2}$ In this definition, rigor indices of $0 \%$ and $100 \%$ represent the pre-rigor and full-rigor states, respectively. Muscle ATP and creatine phosphate were measured by high performance liquid chromatography as reported previously. ${ }^{5}$ Myofibrils and SR were prepared and measured for $\mathrm{Mg}^{2+}$-ATPase activity and $\mathrm{Ca}^{2+}$ uptake rate, respectively, as described in our previous paper. ${ }^{31}$

Figure 1 shows typical results on the courses of muscle ATP and creatine phosphate degradation and rigor index increase during storage at $0^{\circ} \mathrm{C}$ for two carp specimens, one each acclimated to 10 and $30^{\circ} \mathrm{C}$. Though the creatine phosphate concentration fluctuated for both cold- and warm-acclimated carp, their decrease obviously preceded that of ATP. Creatine phosphate is known to donate its phosphate group to ADP enzymatically to keep the ATP concentration constant during an early short period of post-mortem progress. ${ }^{5}$ ATP concentration was main-

Table I. Changes in Biochemical Activity of Myofibrils and Sarcoplasmic Reticulum in Carp Induced by Temperature ACClimation

Carp were acclimated to 10 and $30^{\circ} \mathrm{C}$ and examined in vitro for myofibrillar $\mathrm{Mg}^{2+}$-ATPase activity and sarcoplasmic reticulum $\mathrm{Ca}^{2+}$ uptake rate at a reaction temperature of $0^{\circ} \mathrm{C}$.

\begin{tabular}{|c|c|c|c|c|}
\hline \multirow{2}{*}{$\begin{array}{l}\text { Acclimation } \\
\text { temperature }\end{array}$} & \multicolumn{2}{|c|}{$\begin{array}{c}\text { Myofibrillar } \mathrm{Mg}^{2+}-\mathrm{ATPase} \text { activity }{ }^{a} \\
(\mu \mathrm{mol} \mathrm{Pi} / \mathrm{min} \cdot \mathrm{mg})\end{array}$} & \multicolumn{2}{|c|}{$\begin{array}{c}\text { Sarcoplasmic reticulum } \mathrm{Ca}^{2+} \text { uptake rate } \\
(\mathrm{nmol} \mathrm{Ca} / \mathrm{min} \cdot \mathrm{mg})\end{array}$} \\
\hline & $+\mathrm{Ca}$ & $-\mathrm{Ca}$ & +Oxalate & -Oxalate \\
\hline $10^{\circ} \mathrm{C}$ & $0.130 \pm 0.037^{c, d}$ & $0.003 \pm 0.001$ & $7.17 \pm 0.83$ & $6.23 \pm 0.72^{d}$ \\
\hline $30^{\circ} \mathrm{C}$ & $0.050 \pm 0.004$ & $0.003 \pm 0.001$ & $5.81 \pm 1.20$ & $3.32 \pm 0.67$ \\
\hline
\end{tabular}

a $\mathrm{Mg}^{2+}$-ATPase activity was measured in a reaction mixture containing $5 \mathrm{mM} \mathrm{MgCl}_{2}, 0.1 \mathrm{M} \mathrm{KCl}, 20 \mathrm{mM} \mathrm{Tris-}$ maleate $(\mathrm{pH} 7.0), 2 \mathrm{~mm}$ ATP and $1 \mathrm{mg}$ myofibril $/ \mathrm{ml}$ in the presence of $0.25 \mathrm{mM} \mathrm{CaCl}(+\mathrm{Ca})$ or $1 \mathrm{~mm}$ ethylene glycol bis $\left(\beta\right.$-aminoethylether)- $N, N, N^{\prime}, N^{\prime}$-tetraacetic acid $(-\mathrm{Ca})$.

$b \mathrm{Ca}^{2+}$ uptake rate was measured in a reaction mixture containing $5 \mathrm{~mm} \mathrm{MgCl}, 0.1 \mathrm{M} \mathrm{KCl}, 10 \mathrm{~mm} 3-(N-$ morpholino) propanesulfonic acid-KOH (pH 7.2), $2 \mathrm{mM} \mathrm{ATP} \mathrm{and} 20 \mu \mathrm{M}^{45} \mathrm{CaCl}_{2}(0.196 \mu \mathrm{Ci} / \mathrm{ml})$ in the presence or absence of $5 \mathrm{~mm}$ sodium oxalate.

c Data are given by mean \pm S.E. for three measurements.

d Difference between cold-and warm-acclimated carp is significant at a level of $p<0.01$ for $\mathrm{Mg}^{2+}$-ATPase activity and of $p<0.05$ for $\mathrm{Ca}^{2+}$ uptake rate.

* Present address: Food Science Laboratory, Faculty of Education, Ibaraki University, Mito, Ibaraki 3lo, Japan. 

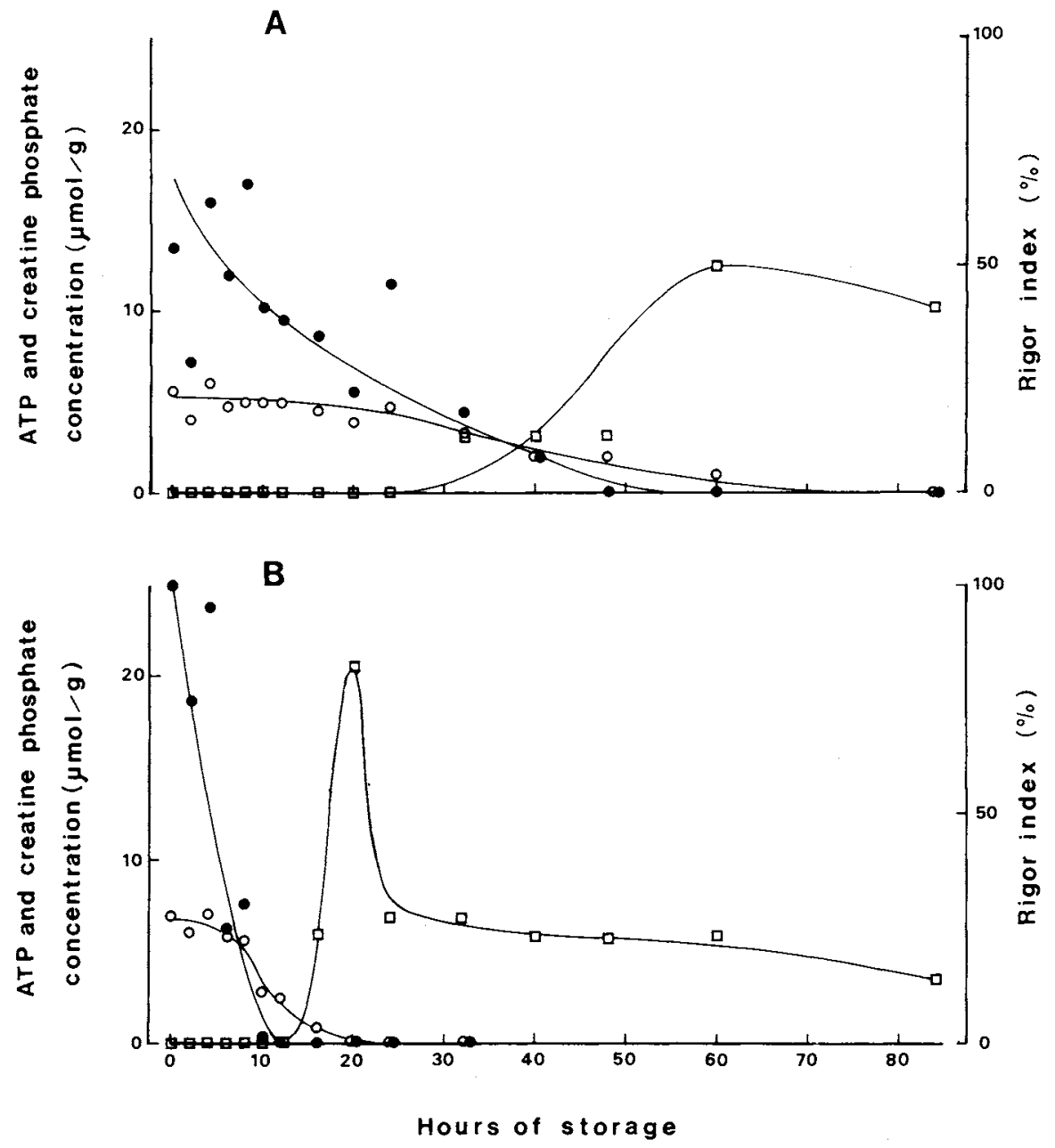

Fig. 1. Rigor-mortis Progress of Carp in Association with Changes in Muscle High-energy Compound Contents.

Carp were acclimated to $10^{\circ} \mathrm{C}(\mathrm{A})$ and $30^{\circ} \mathrm{C}(\mathrm{B})$ and examined for changes in concentration of ATP $(\mathrm{O})$ and creatine phosphate $(O)$ along with progress in the rigor index $(\square)$ during storage at $0^{\circ} \mathrm{C}$.

tained at around $5 \mu \mathrm{mol} / \mathrm{g}$ for $24 \mathrm{hr}$ after death with the cold-acclimated carp and for $8 \mathrm{hr}$ with the warmacclimated one. In association with degradation rates of ATP and creatine phosphate, rigor-mortis progress was retarded in cold-acclimated carp. Its onset was observed $32 \mathrm{hr}$ after death, while it was $16 \mathrm{hr}$ for warm-acclimated carp. The extent of rigor-mortis was much higher with the latter carp. Both cold- and warm-acclimated carp did not attain a full-rigor state and were quickly relaxed after reaching the maximum rigor index values. Lactate accumulation proceeded roughly proportionally to an increase of rigor index and in inverse proportion to ATP degradation (data not shown). Two other experimental groups also had a similar tendency in post-mortem changes (data not shown). However, the onset of rigor-mortis and the period required to attain the maximum value of the rigor index varied considerably depending on rearing conditions such as the tank size and starvation.

To elucidate mechanisms underlying differences in rigor-mortis progress between cold- and warm-acclimated carp, their myofibrillar $\mathrm{Mg}^{2+}$-ATPase activity and SR $\mathrm{Ca}^{2+}$ uptake rate were compared in vitro at a reaction temperature of $0^{\circ} \mathrm{C}$. As shown in Table 1 , myofibrillar $\mathrm{Mg}^{2+}$-ATPase activity in the absence of $\mathrm{Ca}^{2+}$, probably the conditions for decapitated fish, was the same for both carp. However, cold-acclimated carp showed about 3 times the activity in the presence of $\mathrm{Ca}^{2+}$. Therefore, given that the same concentration of $\mathrm{Ca}^{2+}$ is present within both kinds of myofibrils, cold-acclimated carp should deplete ATP more quickly, thus accelerating the progress of rigor- 
mortis. The results obtained were, however, completely opposite. Then we tried to examine $\mathrm{SR} \mathrm{Ca}^{2+}$ uptake. When its rate was measured in the presence of oxalate, which forms a complex with $\mathrm{Ca}^{2+}$ inside the SR membrane, there were observed no significant differences between cold- and warm-acclimated carp. On the other hand, the rate in the absence of oxalate for coldacclimated carp was about twice as high as that for warmacclimated one. Therefore, rigor-mortis acceleration in warm-acclimated carp during storage at $0^{\circ} \mathrm{C}$ is probably attributed to its poor $\mathrm{SR} \mathrm{Ca}^{2+}$ uptake. It is reasonable for cold-acclimated carp to have high myofibrillar $\mathrm{Mg}^{2+}$ ATPase activity and high SR $\mathrm{Ca}^{2+}$ uptake rate, since these carp have the strategy of maintaining locomotory activity patterns under severe conditions of low water temperature. ${ }^{6)}$

Acknowledgment. The expenses of this study were partly defrayed by a Grant-in-Aid for Scientific Research from the Ministry of Education, Science and Culture of Japan.

\section{References}

1) S. P. Heap, P. W. Watt and G. Goldspink, J. Fish Biol., 26, 733 (1985).

2) M. Iwamoto, H. Yamanaka, S. Watabe and K. Hashimoto, J. Food Sci., 52, 1514 (1987).

3) S. Watabe, H. Ushio, M. Iwamoto, H. Yamanaka and K. Hashimoto, J. Food Sci., 54, 1107 (1989).

4) S. Ebashi and M. Endo, Prog. Biophys. Mol. Biol., 18, 123 (1968).

5) M. Iwamoto, H. Yamanaka, H. Abe, H. Ushio, S. Watabe and K. Hashimoto, J. Food Sci., 53, 1662 (1988).

6) H. Guderley and P. Blier, Can. J. Zool., 66, 1105 (1988). 